\title{
Resetting the Future of Healthcare Leadership
}

Anne Wojtak and Neil Stuart

There is no doubt that the events of the past two years will leave an indelible mark on human history. The tragic loss of so many lives during the COVID-19 pandemic, the long-term health and psychological impacts for many more and the economic and societal changes will reverberate for years to come. While the pandemic is not yet over, we are starting to appreciate how different our new future looks and feels. It is within this context that Longwoods Publishing and the Canadian College of Health Leaders (CCHL) have collaborated, for the first time, in a shared reflection on the future of leadership in Canada's healthcare system.

We feel very privileged to have been invited to be guest co-editors of this special edition of Healthcare Quarterly on emerging leadership in healthcare and to partner with CCHL on a special edition of Healthcare Management Forum. We are honoured to have had the opportunity to work with contributing authors from across Canada who have shared their leadership insights within these pages. We are also humbled that our authors were able to do so despite the competing demands on their time during this unprecedented emergency.

As guest co-editors, it has been our role in partnership with the team at Longwoods to consider the question of where healthcare goes from here, and to reflect on the kind of leaders and leadership we will need to shape this new future. It has been an interesting debate as the two of us have different backgrounds and experiences. One of us is a retired career consultant who has worked across the health sector, and the other has spent over two decades working in home and community care and is now leading the development of an integrated system of care. Despite our different pasts, we have found common ground on many issues. We share a view that prior to the pandemic, our health systems and leadership struggled to realize muchneeded large-scale change despite some consensus on the issues and objectives. While we reflected on the reasons for these struggles, we also noted that our slow pace of change is one of the reasons that our systems were ill-prepared to deal with the devastating impact of a global pandemic. We also agreed that as a society, despite decades of warnings, we have failed in our duty to create reliable, safe and personalized care options that meet the needs of older persons. We further recognize that the health inequities that already existed across our society have been fatally exploited by the COVID-19 virus.

\section{Where Do We Go from Here?}

Despite the tragedy of this global pandemic, we also see many signs of hope. Our motivation for working with Longwoods is to promote the leadership lessons we are collectively amassing in real time. This edition on leadership is organized around three themes. The first theme is titled "Leading with Courage and Values" and features reflections on how we move forward with principle-based leadership to address our long-standing health inequities. Our second theme is titled "Leadership Insights from the Pandemic." Here, our contributors emphasize that we cannot waste the once-in-a-generation opportunity that has been presented to us to accelerate change through the new partnerships, structures and processes we have created almost overnight during this global pandemic. Finally, we hear from leaders who share their insights on "Leading in the Future." The final theme highlights the emergent leadership opportunities for our postpandemic world, including leveraging collaborative and distributed leadership, redesigning care systems for our most vulnerable, addressing the interconnectedness of health and environment and, most critically, sharing power and co-creating the future with clients, caregivers and people with lived experience.

In compiling this issue of Healthcare Quarterly, we began with a call for submissions. We received numerous excellent and relevant articles. Several of them focused quite explicitly on leadership through the pandemic. However, we felt there were still some voices and issues that needed attention: the pandemic experience in long-term care, the opioid crisis, an Indigenous perspective and a patient perspective. We were also looking for views on the role of ethics and values in leadership. With this in mind, we asked a few selected leaders if they could each write an opinion-commentary for this leadership edition. Three accepted quickly. Two others agreed to contribute their perspectives by having us interview them. 


\section{Leading with Courage and Values}

This edition begins with a commentary from Anawati and Verma (2021) at the Northern Ontario School of Medicine. They make a compelling case for looking to our leaders for much more than their impact on the bottom-line, financial performance of their organizations. Leaders need to be judged on their efforts to advance a more fair and just society. The authors emphasize doing the right thing through the lens of values and ethics.

A second commentary follows, a remarkable contribution from Harmony Johnson (2021) of the Tla'amin Nation, which explores the challenges and missteps of non-Indigenous healthcare organizations as they attempt to engage with Indigenous representatives. Johnson offers valuable insights into the predicaments faced by Indigenous individuals who agree to work with non-Indigenous health organizations and institutions. Her article suggests strategies for more successful partnerships between organizations and Indigenous Peoples.

The next piece explores the role of leadership in the opioid crisis. It is an interview with Scott Elliott and Patrick McDougall from the Dr. Peter AIDS Foundation in Vancouver (Wojtak and Stuart 2021). Elliott and McDougall speak of the importance of meeting clients/patients where they are and being careful to question dominant assumptions and values. They begin by pointing out that leaders have a fundamental responsibility for clarifying why their organization is there and for appropriately defining the issue or problem that they are addressing. For Elliott and MacDougall, at the heart of their success with the Dr. Peter AIDS Foundation was the reframing of the "problem" the Foundation was addressing. It was not "addictions" but rather "harm reduction."

\section{Leadership Insights from the Pandemic}

The next four articles, in one way or another, all address questions of leadership in the pandemic. Yu et al. (2021) share their experience with a radically different leadership paradigm in the form of distributed leadership in East Toronto Health Partners, which is an integrated system of health and social care. Distributed leadership leverages the power of shared responsibility and accountability across multiple partners to achieve a collective vision rather than relying on the traditional hierarchies and centralized power structures that are common in healthcare. The authors share case examples of how this networked leadership model, which includes a strong role for primary care, enabled a rapid, integrated response to the COVID-19 pandemic in the local community. The lessons learned here are broadly applicable as we look to expand system integration across Canada.

Boechler et al. (2021) give us what is certainly the most heartfelt article in this issue - exploring the experience of paramedics and the role of leadership in their sector in the first wave of the pandemic. Their research taps into the lived experience of front-line paramedics, allowing the authors to draw important lessons about communications, strong relationships with leaders and authenticity in leadership. They conclude their article with several recommendations and helpful takeaways for effective leadership.

Nelson et al. (2021) surveyed emerging leaders in healthcare and asked them to reflect on their leadership behaviour during the pandemic and compare it with that of other leaders in their organizations. Their analysis explores the critical functions of leaders during crises and the challenges leaders experience in following best practices for leading in a crisis.

Patel et al. (2021) provide a graphic account of one of the most critical issues early in the pandemic - the challenges faced by the supply chain and severe shortage of personal protective equipment. The authors draw heavily on the experience of Ontario's Shared Services West. They explore the importance of crisis preparedness, crisis response and resilience. They conclude with several critical lessons learned for future leadership and the next pandemic.

\section{Leaders need to be judged on their efforts to advance a more fair and just society.}

\section{Leading in the Future}

The last group of articles explores the future of leadership in the health sector and what we will need from our leaders to navigate the stormy seas ahead of us.

For several decades now, there has been a drive to achieve better integration of the various elements of healthcare, to break down the "silos of care" and to achieve effective partnership across a multiplicity of health and social care organizations. This is at the heart of the Ontario Health Team (OHT) initiative. Sibbald et al. (2021) present the findings from their study of how the first OHTs in Ontario are establishing their regional integrated care systems. They conclude with a reflective discussion on collaborative leadership.

Next is an interview (Stuart and Wojtak 2021) with Vincent Dumez, co-director of the University of Montreal's Centre of Excellence on Partnership with Patients and the Public. Dumez is one of the most articulate and thoughtful experts on how patients can be critical partners in healthcare and health research. He underlines the foundational role patients can play in healthcare leadership and explains how we need to shift from simply engaging patients to partnering with them.

Szabo (2021) provides a commentary on leadership in long-term care or, more precisely, on the care of seniors more broadly. Cathy Szabo is a long-time leader in the home and community care sector and now chief executive officer of Providence Centre in Kingston, ON. The pandemic in Canada took its highest toll on our nursing homes, where thousands of 
residents died from waves of outbreaks. Breakdowns in care and extended and harmful isolation of residents from their families and friends have had a devastating impact on older persons and their families, as well as on front-line staff. The pandemic highlighted the cumulative failures of past leadership at a policy and system level. Szabo makes an authoritative and urgent call to action, one that every healthcare policy maker in Canada should read and act upon.

The final article is a next-generation perspective on leadership and environmental stewardship from Toccalino et al. (2021). They highlight the environmental impacts of healthcare and the absence of any national strategy to address its environmental sustainability. They describe the work of their network, the Emerging Leaders for Environmental Sustainability in Healthcare, and set out implications for a future strategy on sustainable healthcare.

Taken together, the contributors to this edition of Healthcare Quarterly address many of the issues and shortcomings that have held back healthcare leadership in the past and frustrated the achievement of widely held goals. Some of them explicitly address our experience in the pandemic. They point to a future for healthcare leadership that is highly collaborative with trusted, effective partnerships among organizations and critical stakeholder groups and, most importantly, with patients and their families. A shift to more networked leadership and greater reliance on partnerships does not come easily. It requires a transformation in how we approach leadership. As guest co-editors, we believe the pandemic, despite its many tragic consequences, offers us an opportunity to reset the way we lead healthcare - a reset that will prepare us better for what lies ahead. Let us not waste this opportunity.

\section{References}

Anawati, A. and S. Verma. 2021. Commentary: Moral and Ethical Leadership in the Age of Diversity, Equity, Inclusiveness and Social Accountability. Healthcare Quarterly 24(3): 18-22. doi:10.12927/ hcq.2021.26624.

Boechler, L., C. Cameron, J.C. Smith, P. Ford-Jones and P. Suthers. 2021. Impactful Approaches to Leadership on the Front Lines of the COVID-19 Pandemic: Lived Experiences of Canadian Paramedics. Healthcare Quarterly 24(3): 42-47. doi:10.12927/hcq.2021.26620.
Johnson, H. 2021. Commentary: Laying the Groundwork to Meaningfully Engage Indigenous Leadership. Healthcare Quarterly 24(3): 23-26. doi:10.12927/hcq.2021.26623.

Nelson, W., A. Ruco and I. Dubinsky. 2021. Leadership during a Crisis: Observations by Emerging Leaders during the COVID-19 Pandemic. Healthcare Quarterly 24(3): 48-52. doi:10.12927/hcq.2021.26619.

Patel, R., C. Schmidt, K. Belaire, T. Quigley and R. Repa. 2021. Leading through Crises: Healthcare Supply Chain Strategies and Lessons Learned from the COVID-19 Challenges. Healthcare Quarterly 24(3): 53-57. doi:10.12927/hcq.2021.26618.

Sibbald, S.L., R.E. Hall, G. Embuldeniya, J. Gutberg and W.P. Wodchis. 2021. Foundations, Functions and Current State of Collaborative Leadership: A Case of Newly Developing Integrated Care in Ontario. Healthcare Quarterly 24(3): 60-67. doi:10.12927/hcq.2021.26617.

Szabo, C. 2021. Commentary: The Future of Aging in Canada. Healthcare Quarterly 24(3): 72-75. doi:10.12927/hcq.2021.26615.

Toccalino, D., A.C. Reed, C. Sue-Chue-Lam, A. Cheung and V. Haldane. 2021. Building Environmentally Sustainable Health Systems in Canada: The Time Is Now for Emergent and Strategic Leadership. Healthcare Quarterly 24(3): 76-81. doi:10.12927/hcq.2021.26614.

Stuart, N. and A. Wojtak. 2021. Leadership Perspective: Partnering with Patients to Co-Design Healthcare Systems. Healthcare Quarterly 24(3): 68-71. doi:10.12927/hcq.2021.26616.

Wojtak, A. and N. Stuart. 2021. Leadership Perspective: Addressing Canada's Opioid Crisis - Reducing the Harm of Leadership. Healthcare Quarterly 24(3): 27-30. doi:10.12927/hcq.2021.26622.

Yu, C., K. Chu, J. McCready, S. Downey and T.-N. (Tia) Pham. 2021. Leveraging Innovative Leadership Models within Community and Healthcare Organizations to Support Safe School Reopening during the COVID-19 Pandemic. Healthcare Quarterly 24(3): 34-41. doi:10.12927/hcq.2021.26621.

\section{About the Authors}

Anne Wojtak, DrPH, is a senior healthcare leader with $20+$ years' experience in the home and community care sector in Ontario. She is the lead for East Toronto Health Partners (Ontario Health Team), has a consulting practice focused on health system strategy and is adjunct faculty at the University of Toronto in Toronto, ON. Anne can be contacted at annewojtak@adaptivestrategy.ca.

Neil Stuart, PhD, served for many years as a partner and practice leader in the Canadian healthcare consulting practices of PricewaterhouseCoopers and then IBM. Neil is on the board of Health Standards Organization and has an adjunct faculty appointment in the University of Toronto's Institute of Health Policy, Management and Evaluation in Toronto, ON. Neil can be contacted at neil.stuart@bell.net. 